\title{
Validation of Modified COPCORD Questionnaire Indonesian Version as Screening Tool for Joint Pain and Musculoskeletal Diseases
}

\author{
Muhammad Anshory ${ }^{1}$, C.Singgih Wahono ${ }^{1}$, Handono Kalim¹, Harun Al Rasyid ${ }^{2}$
}

${ }^{1}$ Rheumatology and Allergy Immunology Division, Internal Medicine Department, Faculty of Medicine, Universitas Brawijaya, Saiful Anwar General Hospital, Malang

${ }^{2}$ Public Health and Preventive Medicine Department, Universitas Brawijaya, Malang

\author{
A R T I C L E I N F O \\ Keywords: \\ Validation \\ Questionnaire \\ COPCORD

\section{Corresponding author: \\ Muhammad Anshory MD \\ E-mail address: \\ muhammadanshory@yahoo.com}

All authors have reviewed and approved the final version of the manuscript.

https://doi.org/10.37275/IJR.v10i1.1

\begin{abstract}
A B S T R A C T
Background: WHO-ILAR COPCORD Program is a program that aimed to obtain data on joints pain and musculoskeletal diseases in developing countries, one aspect which has not been studied is the ability of COPCORD questionnaire as a screening tool which standardized for screening joint pain and musculoskeletal diseases. Objective of this study is to assess the validity of modified COPCORD questionnaire Indonesian version in screening joint pain and musculoskeletal disease compared to examination by rheumatologists. Methods: The initial phase of the research is determining essential points, translation to Indonesian, and back translation. The second stage is testing questionnaires in communities which 100 respondents involved. Dependent variable is the diagnosis of rheumatic diseases and independent variables are pain in less and more than 7 days, high degree pain in less and more than 7 days, history of NSAIDs/Steroids/DMARDs use, and disabilities. Validation test was assessed by calculating the sensitivity, specificity, PPV, NPV, LR+, and ROC curve. Bivariate analysis using Chi Square analysis, and multivariate analysis using logistic regression. Results: The sensitivity test results is best obtained on the question history of NSAIDs/steroids/DMARDs use (100\%) and specificity is best obtained on the question about disability (98\%). ROC curve analysis which the results $>85 \%$ obtained on the question of pain $>7$ days $(90 \%)$, high degree pain $>7$ days $(93 \%)$, and history of NSAIDs/steroids/DMARDs use (92\%). LR+ to diagnose rheumatic diseases found in all questions. Chi square analysis showed that all questions were significant with $\mathrm{p}<0.05$ and odds ratio (OR) obtained most on high degree pain more than 7 days (OR: 180.167; 95\% CI: 38.196-849.834).Conclusion: The modified COPCORD questionnaire Indonesian version has been adapted and can be a good tool in the screening of joint pain and musculoskeletal diseases compared to examination by rheumatologists.
\end{abstract}

\section{Introduction}

Joint pain and musculoskeletal disease is the most common cause of morbidity in general population. Even rheumatic diseases not increase mortality but it can lead to disabilities and low quality of life and productivity. ${ }^{1}$ On the other hand the need of data on the magnitude of the problem and the effects of joint and musculoskeletal diseases is very important, especially in developing countries such as Indonesia.
Based on these data we can see the effect of the disease and provide recommendation and intervention plan both in terms of detection and therapy. ${ }^{2}$

In the 1981 the International League against Rheumatism (ILAR) and the World Health Organization (WHO) jointly launched the WHO-ILAR Community Oriented Program for the Control of Rheumatic Diseases (COPCORD) to obtain data on the joints and musculoskeletal diseases in developing countries. 
COPCORD is a low cost program which requires minimal infrastructure by relying on existing resources. Using the same and validated method, COPCORD Phase 1 ( out of 3 phase) has been succeeded to collect data from Australia, ${ }^{3}$ Bangladesh, 4 Brazil, ${ }^{5}$ Chile, ${ }^{5}$ China, ${ }^{6}$ Cuba, ${ }^{7}$ Egypt, ${ }^{8}$ Guatemala, ${ }^{9}$ India,10 Indonesia,11 Iran,12 Kuwait,13 Malaysia,14 Mexico,5, 15 Pakistan,16 Philippines, 17 Thailand,18 Taiwan, 19 Tunisia20 and Vietnam.10, 21-23

One aspect of COPCORD which has not been studied is the ability COPCORD questionnaire as a screening tool that is standardized in rheumatic diseases. For population who has limited health facility level or limited time and resources, this questionnaire would be more suited to be applied in a broad population. The consideration of COPCORD as a standardized tool, requires validation of certain aspects like diagnostic tests, especially when compared to complete examination conducted by rheumatologist. 24 , 25 In the other hand, the adaptation and translation into Indonesian questionnaire also have consequences in language and cultural adaptation that may be different from the original. ${ }^{26}$ Based on this fact, it is necessary to validate a modified COPCORD questionnaire Indonesian version for screening of joint pain and musculoskeletal diseases in Malang.

The aim of this study is to assess the validity of modified COPCORD questionnaire Indonesian version, for screening joint pain and musculoskeletal disease in the population compare to examination done by rheumatologist.

\section{Research Methods}

This research was an analytic study using cross sectional approach, involving 100 respondents consist of Malang's residents. Inclusion criteria for this study are all people aged over 15 years and exclusion criteria are respondents who are unwilling or unable to be interviewed and examined.

The dependent variable in this study was the diagnosis of rheumatic disease, while independent variables were based on the core of the questions in the COPCORD questionnaire which are, the pain are less than 7 days and more than 7 days, high degree pain of less than 7 days and more than 7 days, history of NSAIDs/Steroids/DMARD use, and disabilities. Descriptive statistics in this study were sensitivity, specificity, positive predictive value, negative predictive value, positive likelihood ratio and the ROC curve of each question to the diagnosis of rheumatic disease. This questionnaire is valid if sensitivity and specificity $>80 \%, \mathrm{LR}+>1$ and ROC curve are more than 0.8.27 Chi square analysis method was used to analyze association between two categorical variables. Furthermore, multivariate analysis of the significant variables was done by logistic regression. The analysis was performed with SPSS software version 22.The workflow in this study displayed on picture 1 :

This study conducted in two stage, are stage 1 is an adaptation of COPCORD questionnaire, including:

a. Determine important points in COPCORD questionnaire

In this step, agreement was made on some important points such as pain, degree of pain, therapies which have been obtained and the impact of rheumatic diseases on disability. Questions about ethnicity and religion were eliminated because the population is homogeneous and researchers believe that religion is not associated with joint pain and musculoskeletal disease. In addition, the question about the activity index is adapted from questionnaires GPPAQ 28 .

b. Translating COPCORD quesionnaire into Bahasa Indonesia

The next step was the translation of modified COPCORD questionnaire into Bahasa Indonesia. The translation process was carried out by researchers in join discussions with rheumatologist. Addition of question about physical activity which adapted from GPPAQ in to questionnaire was agreed by researchers. 28 Then, questionnaire was translated back into English by using a third party service from English Language Laboratory, Faculty of Medicine, Brawijaya University.

c. Questionnaire trial and researchers agreement After obtaining a good translation of the COPCORD 
questionnaire into Bahasa Indonesia and evaluation on the back translation, trials conducted on questionnaires with fellow researchers and research agreements. From the test results of this questionnaire show that the words of the questionnaire can be well-received and found interview duration about 30 minutes so researchers can estimate time on the field.

On the stage-2, the community validation study was performed to evaluate the usefulness of modified COPCORD questionnaire Indonesia version to detect joint pain and musculoskeletal diseases compared to physical examination performed by rheumatologists. In this way the sensitivity and specificity of the questionnaire COPCORD compared with clinical diagnosis can be seen and whether the instrument is a good screening tool for joint pain and musculoskeletal diseases in the community.

In this research there was also reliability study to assess internal concistency with cronbach alpha and test retest method analyzed with intraclass correlation coefficient (ICC). Test retest method in this study was done by asking the same questionnaire to 15 random participants twice within 4 weeks interval. ICC value ranged from 0 until 1 and interpreted as follow: 0-0.2 indicate poor agreement: 0.3-0.4 indicate fair agreement, 0.5-0.6 indicate moderate agreement, 0.7-0.8 indicate strong agreement, and $>0.8$ indicate almost perfect agreement. 29

Picture 1. Workflow of Validating COPCORD Questionnaire

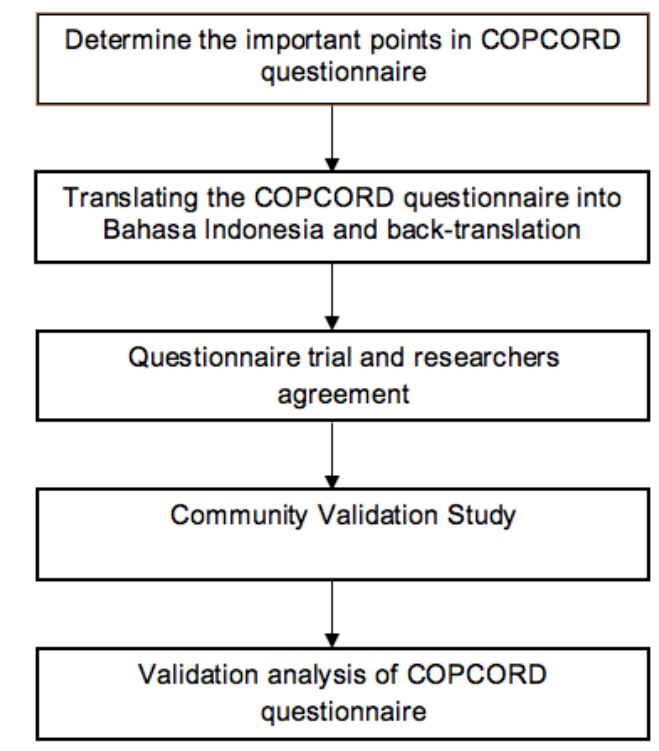

\section{Results}

\section{Sample Baseline Characteristics}

In this research we include 100 respondents in our study. Sample baseline characteristics in this study can be seen in table 1 .

\section{Validation of COPCORD Questionnaire for the screening} of Joint Pain and Musculoskeletal Disease

Validation study in the community, the aim is to see questions' sensitivity and specificity, are: the presence of pain, degree of pain, medication history, and disability. By doing this way we can see the sensitivity and specificity of the modified COPCORD questionnaire Indonesian version compared to clinical diagnosis and investigate whether the instrument is can be used as a good screening tool for joint pain and musculoskeletal diseases in the community.

We present the results of our analysis in the form of sensitivity, specificity, positive predictive value, negative predictive value, likelihood ratio positive (LR + ), and the ROC curve (area under the receiver operating characteristic curve) on how the questions in 
the COPCORD questionnaire can predict clinical evaluation of rheumatic diseases can be seen in table 2. The highest results of the sensitivity among others are on the question about history of pain over 7 days $(92 \%)$, high degree pain (pain with VAS> 4/10) at pain over 7 days (92\%), and history of NSAIDs/steroids/DMARDs use (100\%). While the highest specificity obtained on question about high degree pain on pain of less than 7 days (96\%), a high degree of pain on pain of more than 7 days (94\%) and the disability $(98 \%)$.

ROC curve analysis with the results $>85 \%$ obtained on the question of pain $>7$ days $(90 \%)$, high degree pain $>7$ days (93\%), history of NSAIDs/Steroids/DMARDs use $(92 \%)$ showed a strong predictive value against rheumatic diseases diagnosis.

Additionally, LR $+>1$ to the diagnosis of rheumatic disease was found in all the questions, pain in less than 7 days, history of pain more than 7 days, high degree pain of less than 7 days, history of high degree pain of more than 7 days, history of NSAIDs/steroids/DMARDs use and disability according to MHAQ. These variables were analyzed using chi square analysis showed that all the questions were significance with $\mathrm{p}<0.05$ with odds ratio (OR) obtained at the most from history of high degree pain $(\mathrm{VAS}>4)$ more than 7 days, OR $=180.167(95 \% \mathrm{CI}$ 38.196-849.834). The results of bivariate analysis can be seen on table 3 .

Multivariate analysis on the questions carried out simultaneously by logistic regression do not show significant results.

The reliability study showed that cronbach alpha analysis is good in all question with coefficient ranged from 0.737 until 1.000. While analysis with ICC the result ranged from 0.754 until 1.000 . The results of reliability study can be seen on table 4.

Table 1. Sample Baseline Characteristics

\begin{tabular}{|c|c|}
\hline Characteristics & $\begin{array}{c}\text { Percentage } \\
\quad N=100\end{array}$ \\
\hline \multicolumn{2}{|c|}{ Rheumatic Disease } \\
\hline Yes & 50 \\
\hline No & 50 \\
\hline \multicolumn{2}{|l|}{ Pain $<7$ hari } \\
\hline Yes & 39 \\
\hline No & 61 \\
\hline \multicolumn{2}{|l|}{ Pain $>7$ hari } \\
\hline Yes & 52 \\
\hline No & 48 \\
\hline \multicolumn{2}{|c|}{ High degree pain < 7 hari (VAS >4/10) } \\
\hline Yes & 15 \\
\hline No & 85 \\
\hline \multicolumn{2}{|c|}{ High degree pain $>7$ hari (VAS $>4 / 10$ ) } \\
\hline Yes & 49 \\
\hline No & 51 \\
\hline \multicolumn{2}{|c|}{ History of NSAID/Steroid/DMARD use } \\
\hline Yes & 58 \\
\hline No & 42 \\
\hline \multicolumn{2}{|l|}{ Disability } \\
\hline Yes & 16 \\
\hline No & 84 \\
\hline
\end{tabular}

High degree pain: pain with visual analog scale >4/10, NSAID: Non Steroidal Anti Inflammatory Drug, DMARD: 
Disease Modifying Anti Rheumatoid Drug, LR (+): Positive Likelihood Ratio, ROC: area under the receiver operating characteristic curve

Picture 1. ROC Curve of COPCORD Questionnaire Points against Rheumatic Disease Diagnosis

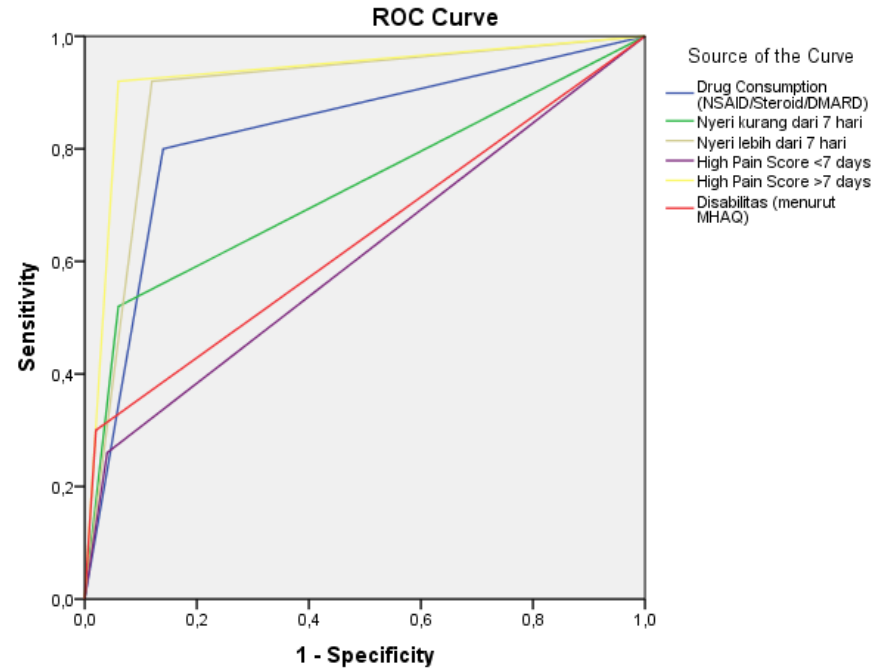

Table 2. Diagnostic Test of COPCORD Questionnaire Points against Rheumatic Disease Diagnosis

\section{COPCORD Questions}

Pain $<7$ days

Pain $>7$ days

High degree pain $<7$ days

High degree pain $>7$ days

History of

NSAID/Steroid/DMARD use

Disability

Rheumatic Disease Diagnosis $(n=100)$

\begin{tabular}{cccccc}
$\begin{array}{c}\text { Sensitivity } \\
(\%)\end{array}$ & $\begin{array}{c}\text { Specificity } \\
(\%)\end{array}$ & $\begin{array}{c}\text { PPV } \\
(\mathbf{\%})\end{array}$ & $\begin{array}{c}\text { NPV } \\
(\mathbf{\%})\end{array}$ & $\begin{array}{c}\text { LR } \\
(+)\end{array}$ & ROC \\
\hline 64 & 86 & 82 & 70 & 6.25 & 0.75 \\
92 & 88 & 88 & 92 & 4.57 & 0.90 \\
26 & 96 & 87 & 56 & 7.67 & 0.61 \\
92 & 94 & 94 & 92 & 6.5 & 0.93 \\
100 & 84 & 86 & 100 & 15.3 & 0.92 \\
30 & 98 & 94 & 58 & 15 & 0.64 \\
\hline
\end{tabular}

Table 3. Analysis of Each COPCORD Questionnaire Points against Rheumatic Disease Diagnosis

\begin{tabular}{llll}
\hline COPCORD Questions & P & OR & 95\% CI \\
\hline Pain $<7$ days & $<0.001$ & 10.921 & $4.075-29.263$ \\
Pain $>7$ days & $<0.001$ & 84.333 & $22.283-319.171$ \\
High degree pain $<7$ days & 0.002 & 8.432 & $1.791-39.698$ \\
High degree pain $>7$ days & $<0.001$ & 180.167 & $38.196-849.834$ \\
History of NSAID/Steroid/ DMARD & $<0.001$ & - & - \\
use & $<0.001$ & 21.000 & $2.649-166.454$ \\
Disability & & & \\
\hline
\end{tabular}

High degree pain: pain with visual analog scale >4/10, NSAID: Non Steroidal Anti Inflammatory Drug, DMARD: Disease Modifying Anti Rheumatoid Drug, OR: Odd Ratio, CI: Confidence Interval 
Tabel 4. Reliability Study of Each COPCORD Questionnaire Points

\begin{tabular}{lccc}
\hline COPCORD Questions & Cronbach Alpha & ICC & p \\
\hline Pain $<7$ days & 0.756 & 0.767 & 0.004 \\
Pain $>7$ days & 0.737 & 0.754 & 0.005 \\
High degree pain $<7$ days & 0.772 & 0.754 & 0.005 \\
High degree pain $>7$ days & 0.822 & 0.808 & 0.001 \\
History of NSAID/Steroid/ DMARD use & 1.000 & 1.000 & $<0.001$ \\
Disability & 0.737 & 0.754 & 0.005 \\
\hline
\end{tabular}

ICC: Intraclass Correlation Coefficient

\section{DISCUSSION}

Questionnaire as a tool is already frequently used in medical research. By the increasing number of multinational and multicultural research, the need of adaptation to the questionnaire which has been used in languages other than English also growing rapidly because most of the questionnaire are in English. 30 The need of adaptation to the language and culture become important in Asia-Pacific because of the need of data on rheumatic diseases. Hopefully the questionnaire will produce a study about the identification of risk factors and at the same time it will ensure the uniformity of data, and if collected, could be identification of risk factors with high quality and precision. Generally, most of questionnaires were made in English but only a few population who uses English as daily language. Therefore, there was a necessary to adapt questionnaires into local language and culture. ${ }^{31}$

This study was conducted to determine the ability of modified COPCORD questionnaire Indonesian version as a screening tool for rheumatic diseases. The questionnaire was validated and applied as a screening tool to detect musculoskeletal disorders in the community, especially in developing countries like Indonesia.Until now its ability to identify patients with joint pain and musculoskeletal disease still need further investigation, especially in Indonesia. However, a similar study has been done in other COPCORD research $6,32,33$

In this study, the adaptation is done by selecting the important points which are already covered in the questionnaire COPCORD that has been validated in multiple languages before. Selection of these points affect to the removal of questions on ethnicity and religion, it because religion does not affect the joints pain and musculoskeletal diseases. ${ }^{34}$ Although ethnicity play an important role in the incidence of some joints and muskuloskeletal diseases ,34 there is no ethnic differences in people of Malang.

Besides, the modifications were made by addition question about physical activity which adapted from questionnaires GPPAQ used by the health department in the UK, ${ }^{34}$ The additional questioncan also be used to measure the level of daily activity, so we can see if there a relationship between the activities of a person with the incidence of joint pain and musculoskeletal diseases. In the UK, the questionnaire is used to assess person's activity level, so it can give some advice to person to act an active lifestyle to avoid the various chronic and metabolic diseases caused by inactive lifestyle 35 .

The key points are selected in this analysis include pain in less than 7 days and more than 7 days, high degree pain in less than 7 days and more than 7 days, history of NSAIDs/Steroids/DMARDs use, and disabilities. It based on the definition of joint pain and musculoskeletal diseases are collection of symptoms include joint pain, swelling and/or limitation of motion. Therefore by asking if any joint pain in the form of signs of joint pain, and/or soft tissue/musculoskeletal pain, and/or joint swelling, and/or stiffness of the joints and/or stiffness in the spine, and/or reduced movement on any joint and/or reduced movement in spine or neck are expected to see their joint pain and musculoskeletal diseases then it would be confirmed by 
physical examination.

Adding a category about high degree of pain is based on the results of a previous study by Bennett, et al which was cross-cultural adaptation and validation of the questionnaire COPCORD in Mexico, originally the sensitivity and specificity of the questionnaire COPCORD was $84 \%$ and $61.3 \%$, but by adding a category based on VAS pain score $>4$, the sensitivity decreased to $42.7 \%$ and the specificity increased to $80 \%, 36$ so the researchers decided to use both components of the pain question. In this study, variable about duration of pain and high degree of pain have high sensitivity and specificity (Pain < 7 days: sensitivity 64\%, specificity 86\%; Pain $>7$ days: sensitivity $92 \%$, specificity $88 \%$; High degree of pain <7 days: sensitivity $26 \%$, specificity 96\%; High degree of pain > 7 days: sensitivity $92 \%$, specificity 94\%). It indicates that the questionnaire can be a good screening tool for joint pain and musculoskeletal diseases.

Questions about the use of medicines such as NSAIDs, DMARDs and steroids also affect the diagnosis of joint and musculoskeletal disease which in patients with joint pain and musculoskeletal disease pain are the main complaint so that patients will seek treatment to relief the pain either by self treatment or by going to the doctor, and the treatment carried out in the short term or long term, depending on the patient's perceived pain. Usually patients who have been diagnosed with joints and musculoskeletal diseases will get treatment from doctors such as pain killer or other drugs to slow or halt the disease process such as steroids or DMARD. ${ }^{37}$ The variable about history of drug use whether NSAIDs, steroids and DMARD has sensitivity $100 \%$ and specificity of $84 \%$. It indicates that all respondents who have diagnosed joint disease and musculoskeletal disease, not all of them take drugs in accordance with indication.

Questions about disability in this study was adapted from MHAQ questionnaires, which has relationship between disability and joint pain and musculoskeletal disease. 38 In this study, obtained with a sensitivity $30 \%$ and specificity $98 \%$, illustrating that the question is specific but not sensitive to patients with a diagnosis of joint pain and musculoskeletal disease.

After determining the important points, translation and back translation was done by linguists to ensure that no significant changes during the translation process that will change the meaning or intent of the questions.

COPCORD modified questionnaire in this study can serve as a tool to measure magnitude of the epidemiology of joint pain and musculoskeletal disease and also to assess the risk factors that influences to the diseases. This questionnaireis expected not only can be used by clinicians as a screening tool for joint pain and musculoskeletal disease, but also applicable for other health professionals such as paramedics.

In a population study at Mexico by Robles, et al there are four variables which have good performance in diagnostic tests are: pain in the past 7 days, the high degree of pain, history of treatment with NSAIDs, and earlier diagnosis. However, these results vary in certain diseases, such as in Osteoarthritis (OA).. Most of significant question of $\mathrm{OA}$ is a pain in the last 7 days, HAQ score, and earlier diagnosis; for Rheumatic Regional Pain Syndrome (RRPS), just a pain in the last 7 days; and for Rheumatoid Arthritis (RA) (in addition to the 4 questions) are history of pain without trauma, use of NSAIDs, HAQ score, and physical limitations are reported all correlated with the diagnosis. In addition, it is estimated that the questions that have $\mathrm{LR}+\geq 2$, showed a clear correlation with the diagnosis of arthritis which can be applied at population. 25 Another study in the Philippines by Dans, et al found that the sensitivity of the COPCORD questionnaire was $91 \%$ (95\% CI, 85-95) while the specificity was 51\% (95\% CI, 43-59).39 This association indicates that the questionnaire could be implemented as part of the referral process, start from primary care to specialist care. It is because important considerations should be noted in the screening test addition is the questions not only having adequate sensitivity but also it has high specificity.

The questionnaire in this study meet these requirements, which some variables have good 
sensitivity such as the history of pain over 7 days (92\%), high degree of pain (pain with VAS> 4/10) at pains over 7 days (92\%), and history of drug use (NSAIDs/dsteroid/DMARD) (100\%) and specificity of the question : high degree of pain which less than 7 days (96\%), high degree of pain which more than 7 days $(94 \%)$ and the presence of disability (98\%), makes the questionnaire is more specific than sensitive. The result of reliability study with cronbach alpha dan ICC in this study showed good result with coefficient of Cronbach alpha ranged from 0.737 until 1.000. While ICC analysis results ranged from 0.754 until 1.000. Landis and $\mathrm{Koch}^{29}$ stated that value 0.7-0.8 indicates strong agreement, and value $>0.8$ indicates almost perfect agreement this result showed that the questionnaire is reliable in diagnosis of joint pain and musculoskeletal diseases.

The benefits of COPCORD questionnaire can detect a common rheumatic disease which can help patients to promptly diagnosed and treated by rheumatologists. It is becoming an alternative in developing countries where health systems are still not well organized like in Indonesia. Moreover in the first-level health facilities, efficient guides for detecting rare cases and health facilities are still inadequate. This questionnaire method in the first-level health facility is needed to be introduced for screening rheumatic disease. Woolf, et al wrote a persuasive article about prevention of musculoskeletal diseases, especially in developing countries ${ }^{40}$, and give a number of recommendations, such as: (1) effective prevention and control against musculoskeletal diseases as a priority, (2) increasing public and individual awareness about issues which relate to musculoskeletal disease such as spreading a good quality information, (3) and the need of early diagnosis the musculoskeletal disease.

The advantages of this questionnaire is easy to carry out the screening process because it requires minimal resources, so that it can reach all health professionals, especially in developing countries like in Indonesia. Therefore we can obtain epidemiological data that would support health planning system and as an initial screening for diagnosis of joint pain and musculoskeletal diseases in the wider community.

But the obstacles that may be encountered is the questionnaire consist of many questions which could be make the respondent and interviewer feel bored or uncooperative during the interview process. It can be repaired with practice regularly, so the interviewer can ask nicely without makes respondents feel bored and cooperative during the interview process.

\section{CONCLUSION}

Modified COPCORD Questionnaire to Indonesian Version has been adapted and can be asa good tool in screening and detection of joint pain and musculoskeletal diseases, especially in Indonesia. This questionnaire has good sensitivity and specificity, so it can be a valid and effective tool for screening joint pain and musculoskeletal diseases compared to examination by rheumatologists

The authors suggest for the application of a modified version of the questionnaire COPCORD Indonesian in epidemiological studies especially on basic health facilities as a first step in screening for joint pain and musculoskeletal diseases in Indonesian society.

\section{REFERENCES}

1. WHO. The burden of musculoskeletal conditions at the start of the new millennium. World Health Organ Tech Rep Ser. 2003;919:i-x, 1-218, back cover. PubMed PMID: 14679827. Epub 2003/12/19. eng.

2. Ferraz MB. Community orients program for the control of rheumatic diseases Copcord project in Brazil and Latin America. Sao Paulo Med J. 1995;113(2).

3. Minaur N, Sawyers S, Parker J, Darmawan J. Rheumatic disease in an Australian Aboriginal community in North Queensland, Australia. A WHO-ILAR COPCORD survey. J Rheumatol. 2004;31(5):965-972.

4. Haq SA, Darmawan J, Islam MN, Uddin MZ, Das $\mathrm{BB}$, Rahman F, et al. Prevalence of rheumatic diseases and associated outcomes in rural and 
urban communities in Bangladesh: a COPCORD study. J Rheumatol. 2005 Feb;32(2):348-353.

5. Bennett K, Cardiel MH, Ferraz MB, Riedemann P, Goldsmith $\mathrm{CH}$, Tugwell P. Community screening for rheumatic disorder: cross cultural adaptation and screening characteristics of the COPCORD Core Questionnaire in Brazil, Chile, and Mexico. The PANLAR-COPCORD Working Group. Pan American League of Associations for Rheumatology. Community Oriented Programme for the Control of Rheumatic Disease. $J$ Rheumatol. 1997 Jan;24(1):160-168.

6. Wigley RD, Zhang NZ, Zeng QY, Shi CS, Hu DW, Couchman K, et al. Rheumatic diseases in China: ILAR-China study comparing the prevalence of rheumatic symptoms in northern and southern rural populations. J Rheumatol. 1994 Aug;2 1(8):1484-1490.

7. Reyes Llerena GA, Guibert Toledano M, Hernandez Martinez AA, Gonzalez Otero ZA, Alcocer Varela J, Cardiel $\mathrm{MH}$. Prevalence of musculoskeletal complaints and disability in Cuba. A communitybased study using the COPCORD core questionnaire. Clin Exp Rheumatol. 2000 NovDec;18(6):739-742.

8. Abdel-Tawab R, Abdel-Nasser A, Darmawan J. The prevalence of rheumatic diseases in rural Egypt: COPCORD-Egypt. Abstract Proceedings Book, 11 th APLAR Congress. APLAR: Jeju, Korea; 2004.

9. Obregon-Ponce A, Iraheta I, Garcia-Ferrer H, Mejia B, Garcia-Kutzbach A. Prevalence of musculoskeletal diseases in Guatemala, Central America: the COPCORD study of 2 populations. J Clin Rheumatol. 2012 Jun;18(4):170-174.

10. Joshi VL, Chopra A. Is there an urban-rural divide? Population surveys of rheumatic musculoskeletal disorders in the Pune region of India using the COPCORD Bhigwan model. $J$ Rheumatol. 2009 Mar;36(3):614-622.

11. Darmawan J, Valkenburg HA, Muirden KD, Wigley RD. Epidemiology of rheumatic diseases in rural and urban populations in Indonesia: a World Health Organisation International League Against Rheumatism COPCORD study, stage I, phase 2.
Ann Rheum Dis. 1992 Apr;51(4):525-528.

12. Davatchi F, Jamshidi AR, Banihashemi AT, Gholami J, Forouzanfar MH, Akhlaghi M, et al. WHO-ILAR COPCORD Study (Stage 1, Urban Study) in Iran. J Rheumatol. 2008 Jul;35(7):1384.

13. Al-Awadhi A, Olusi S, Moussa M, Al-Zaid N, Shehab D, Al-Herz A, et al. Validation of the Arabic version of the WHO-ILAR COPCORD Core Questionnaire for community screening of rheumatic diseases in Kuwaitis. World Health Organization. International League Against Rheumatism. Community Oriented Program for the Control of Rheumatic Diseases. J Rheumatol. 2002 Aug;29(8):1754-1759.

14. Veerapen K, Wigley RD, Valkenburg $H$. Musculoskeletal pain in Malaysia: a COPCORD survey. J Rheumatol. 2007 Jan;34(1):207-213.

15. Pelaez-Ballestas I, Sanin LH, Moreno-Montoya J, Alvarez-Nemegyei J, Burgos-Vargas R, GarzaElizondo M, et al. Epidemiology of the rheumatic diseases in Mexico. A study of 5 regions based on the COPCORD methodology. J Rheumatol Suppl. 2011 Jan;86:3-8.

16. Farooqi A, Gibson T. Prevalence of the major rheumatic disorders in the adult population of north Pakistan. $\mathrm{Br} \mathrm{J}$ Rheumatol. 1998 May;37(5):491-495.

17. Dans LF, Tankeh-Torres S, Amante CM, Penserga EG. The prevalence of rheumatic diseases in a Filipino urban population: a WHO-ILAR COPCORD Study. World Health Organization. International League of Associations for Rheumatology. Community Oriented Programme for the Control of the Rheumatic Diseases. J Rheumatol. 1997 Sep;24(9):1814-1819.

18. Chaiamnuay $\mathrm{P}$, Darmawan J, Muirden KD, Assawatanabodee P. Epidemiology of rheumatic disease in rural Thailand: a WHO-ILAR COPCORD study. Community Oriented Programme for the Control of Rheumatic Disease. J Rheumatol. 1998 Jul;25(7):1382-1387.

19. Chou CT, Pei L, Chang DM, Lee CF, Schumacher HR, Liang MH. Prevalence of rheumatic diseases in Taiwan: a population study of urban, suburban, 
rural differences. J Rheumatol. 1994 Feb;21(2):302-306.

20. Laatar A, Hajem S, Kerkeni S, Chekili S, Belhassine B, Hajri R, et al. Prevalence of Musculoskeletal Complaints and Disability in Tunisia: A WHO-ILAR Copcord Study. Ann Rheum Dis. 2005;64(Supp1.III):550.

21. Chopra A. The COPCORD world of musculoskeletal pain and arthritis. Rheumatology (Oxford). 2013 Nov;52(11):1925-1928.

22. Chopra A, Abdel-Nasser A. Epidemiology of rheumatic musculoskeletal disorders in the developing world. Best Pract Res Cl Rh. 2008 Aug;22(4):583-604.

23. Minh Hoa TT, Darmawan J, Chen SL, Van Hung N, Thi Nhi C, Ngoc An T. Prevalence of the rheumatic diseases in urban Vietnam: a WHOILAR COPCORD study. J Rheumatol. 2003 Oct;30(10):2252-2256.

24. Pelaez-Ballestas I, Granados Y, Silvestre A, Alvarez-Nemegyei J, Valls E, Quintana R, et al. Culture-sensitive adaptation and validation of the community-oriented program for the control of rheumatic diseases methodology for rheumatic disease in Latin American indigenous populations. Rheumatol Int. 2014 Sep;34(9):1299-1309.

25. Goycochea-Robles M-V, SANIN LH, MorenoMontoya J, Alvarez-Nemegyei J, Burgos-Vargas R, Garza-Elizondo M, et al. Validity of the COPCORD core questionnaire as a classification tool for rheumatic diseases. J Rheumatol. 2011;86:31-35.

26. Kleinman A, Benson P. Anthropology in the clinic: the problem of cultural competency and how to fix it. PLoS Med. 2006 Oct;3(10):e294. PubMed PMID: 17076546.

27. Šimundić A-M. Measures of diagnostic accuracy: basic definitions. Med Biol Sci. 2008;22(4):61-65.

28. Department of Health. The General Practice Physical Activity Questionnaire: A Screening tool to assess adult physical activity levels, within primary care. 2009. [https://www.gov.uk/government/uploads/syste $\mathrm{m} /$ uploads/attachment_data/file/192453/GPPA Q_-_guidance.pdf]
29. Landis JR, Koch GG. The measurement of observer agreement for categorical data. Biometrics. 1977:159-174.

30. Guillemin F, Bombardier C, Beaton D. Crosscultural adaptation of health-related quality of life measures: literature review and proposed guidelines. J Clin Epidemiol. 1993;46(12):14171432.

31. Haq SA, Davatchi F, Dahaghin S, Islam N, Ghose A, Darmawan J, et al. Development of a questionnaire for identification of the risk factors for osteoarthritis of the knees in developing countries. A pilot study in Iran and Bangladesh. An ILAR-COPCORD phase III study. Int J Rheum Dis. 2010;13(3):203-214.

32. Chopra A, Patil J, Billempelly V, Relwani J, Tandle H. Prevalence of rheumatic diseases in a rural population in western India: a WHO-ILAR COPCORD Study. J Assoc Physicians India. 2001;49:240-246.

33. Gamboa R, Medina M, Acevedo E, Pastor C, Cucho M, Gutierrez C. Prevalence of rheumatic diseases and disability in an urban marginal Latin American population. A community based study using the COPCORD model. Arthritis Rheum. 2007;9:S344.

34. Kumar K, Klocke R. Ethnicity in rheumatic disease. Clin Med (Northfield Il). 2010;10(4):370372.

35. Heron N, Tully MA, McKinley MC, Cupples ME. Physical activity assessment in practice: a mixed methods study of GPPAQ use in primary care. BMC Fam Pract. 2014;15(1): 1 .

36. Bennett K, Cardiel M, Ferraz M, Riedemann P, Goldsmith C, Tugwell P. Community screening for rheumatic disorder: cross cultural adaptation and screening characteristics of the COPCORD Core Questionnaire in Brazil, Chile, and Mexico. The PANLAR-COPCORD Working Group. Pan American League of Associations for Rheumatology. Community Oriented Programme for the Control of Rheumatic Disease. $J$ Rheumatol. 1997;24(1):160-168.

37. Roberts E. Medications Used to Treat Rheumatic 
Diseases. Internet. 2009. [Cited Date: 10 September 2016]. Available from:

http:/ / www.everydayhealth.com/rheumatic-

diseases/medications-used-to-treat-rheumatic-

diseases.aspx.

38. Hawley DJ, Wolfe F. Pain, disability, and pain/disability relationships in seven rheumatic disorders: a study of 1,522 patients. J Rheumatol. 1991;18(10):1552-1557.

39. Dans LF, Fabia S, Tanopo L, Lorenzo JP, Lim J. Rheumatic diseases in the Philippines: Validation of the copcord core questionnaire against physical examination. J Clin Epidemiol. 1996;49:S4.

40. Woolf AD, Brooks P, Åkesson K, Mody GM. Prevention of musculoskeletal conditions in the developing world. Best Pract Res Clin Rheumatol. 2008;22(4):759-772. 